\title{
Respiratory Effects of Exposure to Diesel Traffic in Persons with Asthma
}

\author{
James McCreanor, M.R.C.P., Paul Cullinan, M.D., MarkJ. Nieuwenhuijsen, Ph.D., \\ James Stewart-Evans, M.Sc., Eleni Malliarou, M.Sc., Lars Jarup, Ph.D., \\ Robert Harrington, M.S., Magnus Svartengren, M.D., In-Kyu Han, M.P.H., \\ Pamela Ohman-Strickland, Ph.D., Kian Fan Chung, M.D., \\ and Junfeng Zhang, Ph.D.
}

From the National Heart and Lung Institute, Imperial College, and Royal Brompton Hospital (J.M., P.C., K.F.C.) and the Department of Epidemiology and Public Health, Imperial College (J.S.-E., E.M., L.J.) - all in London; the Center for Research in Environmental Epidemiology, Barcelona (M.J.N.); the University of Medicine and Dentistry of New Jersey School of Public Health, Piscataway (R.H., I.-K.H., P.O.-S. J.Z.); and the Department of Public Health Sciences, Karolinska Institutet, Stockholm (M.S.). Address reprint requests to $\mathrm{Dr}$. Cullinan at the Department of Occupational and Environmental Medicine, National Heart and Lung Institute, lb Manresa Rd., London SW3 6LR, United Kingdom, or at p.cullinan@imperial.ac.uk.

N Engl J Med 2007;357:2348-58.

Copyright (@) 2007 Massachusetts Medical Society.

\section{ABSTRACT}

\section{BACKGROUND}

Air pollution from road traffic is a serious health hazard, and people with preexisting respiratory disease may be at increased risk. We investigated the effects of short-term exposure to diesel traffic in people with asthma in an urban, roadside environment.

\section{METHODS}

We recruited 60 adults with either mild or moderate asthma to participate in a randomized, crossover study. Each participant walked for 2 hours along a London street (Oxford Street) and, on a separate occasion, through a nearby park (Hyde Park). We performed detailed real-time exposure, physiological, and immunologic measurements.

\section{RESULTS}

Participants had significantly higher exposures to fine particles $(<2.5 \mu \mathrm{m}$ in aerodynamic diameter), ultrafine particles, elemental carbon, and nitrogen dioxide on Oxford Street than in Hyde Park. Walking for 2 hours on Oxford Street induced asymptomatic but consistent reductions in the forced expiratory volume in 1 second $\left(\mathrm{FEV}_{1}\right)$ (up to 6.1\%) and forced vital capacity (FVC) (up to 5.4\%) that were significantly larger than the reductions in $\mathrm{FEV}_{1}$ and FVC after exposure in Hyde Park $(\mathrm{P}=0.04$ and $\mathrm{P}=0.01$, respectively, for the overall effect of exposure, and $\mathrm{P}<0.005$ at some time points). The effects were greater in subjects with moderate asthma than in those with mild asthma. These changes were accompanied by increases in biomarkers of neutrophilic inflammation (sputum myeloperoxidase, $4.24 \mathrm{ng}$ per milliliter after exposure in Hyde Park vs. $24.5 \mathrm{ng}$ per milliliter after exposure on Oxford Street; $\mathrm{P}=0.05$ ) and airway acidification (maximum decrease in $\mathrm{pH}, 0.04 \%$ after exposure in Hyde Park and $1.9 \%$ after exposure on Oxford Street; $\mathrm{P}=0.003$ ). The changes were associated most consistently with exposures to ultrafine particles and elemental carbon.

\section{CONCLUSIONS}

Our observations serve as a demonstration and explanation of the epidemiologic evidence that associates the degree of traffic exposure with lung function in asthma. 
IR POLLUTION FROM ROAD TRAFFIC IS a serious health hazard, and particulates from diesel exhaust have become cause for increasing concern. Epidemiologic studies have demonstrated associations between ambient particulate matter and respiratory-associated morbidity and mortality; these effects may be greater among persons with preexisting respiratory disease, including asthma. ${ }^{1,2}$

Diesel engines emit relatively low concentrations of carbon monoxide and carbon dioxide, but as compared with gasoline engines of similar size, diesel engines can generate more than 100 times the number of particles per distance traveled ${ }^{3}$ and are major contributors to atmospheric particulate pollution. In urban environments, almost $90 \%$ of traffic-generated particulate matter is from diesel exhaust. ${ }^{4,5}$

Many urban residents, including those with increased susceptibility to the effects of air pollution, have short-term exposure to diesel traffic during normal activities. Studies of humans in exposure chambers have shown that controlled exposure to diesel exhaust can provoke increased airway resistance $e^{6,7}$ and bronchial inflammatory changes. ${ }^{8-11}$ Such studies are limited by their artificial nature, however, and the small numbers of study participants have typically been healthy.

We explored the effects of roadside traffic exposure on people with mild or moderate asthma, of differing severity, on a busy city street where traffic is entirely diesel-powered. We tested the hypothesis that short-term, ambient exposures to diesel traffic would lead to a reduction in lung function and a worsening of symptoms, accompanied by increased inflammation in the lungs.

\section{METHODS}

\section{PARTICIPANTS}

Using advertising and volunteer databases, we recruited 60 adults with asthma, none of whom were smokers; 31 had mild asthma and 29 had moderate asthma, as defined by the Global Initiative for Asthma. ${ }^{12}$ Each participant had intermittent wheezing and airway hyperresponsiveness to methacholine; the concentration of methacholine required to provoke a $20 \%$ decrease $\left(\mathrm{PC}_{20}\right)$ in the forced expiratory volume in 1 second $\left(\mathrm{FEV}_{1}\right)$ was $<8 \mathrm{mg}$ per milliliter. The participants were studied during periods of asthmatic stability, defined by the absence of exacerbations, respiratory infec- tions, and treatment with oral corticosteroids for 4 weeks or more. During the study, the participants took their usual asthma medications.

The project was approved by the ethics committee at Brompton Hospital, London, and the institutional review board at the Robert Wood Johnson Medical School, New Brunswick, New Jersey. Written informed consent was provided by all participants.

\section{STUDY DESIGN}

In this randomized, crossover study, participants walked for 2 hours (10:30 a.m. to 12:30 p.m.) along the western end of Oxford Street, London's busiest shopping street, where only diesel-powered buses and taxicabs are permitted, or through the traffic-free, western part of the nearby 142-hectare (about 350-acre) Hyde Park. Participants walked about $6 \mathrm{~km}$ during each exposure, at a steady pace on predefined paths, resting for 15 minutes every half hour. Exposure sessions, separated by more than 3 weeks, were confined to weekdays between November and March (2003 to 2005) to avoid pollen seasons; rainy days were also avoided. Equal numbers of participants were randomly assigned to each exposure sequence. The study had an estimated $90 \%$ power to detect a minimum difference in $\mathrm{FEV}_{1}$ response of $5.7 \%$ in each asthmaseverity group between the two sites.

\section{CLINICAL MEASUREMENTS}

Participants measured their peak expiratory flow on a mini-Wright meter and recorded asthma symptoms 1 week before and after each exposure session; during the week before each exposure, they wore a diffusion tube to measure individual exposure to nitrogen dioxide throughout the week. At Royal Brompton Hospital, baseline measurements of $\mathrm{FEV}_{1}$, forced vital capacity (FVC), and forced expiratory flow at 25 to $75 \%$ of vital capacity $\left(\mathrm{FEF}_{25-75}\right)$ were performed with the use of a spirometer (Vitalograph); the fraction of exhaled nitric oxide $\left(\mathrm{FE}_{\mathrm{NO}}\right)$ was recorded with the use of a chemiluminescence analyzer (Aerocrine). Exhaled breath condensate from tidal breathing was obtained with the use of a standardized breath-condensate collector (ECoScreen, Jaeger), and its $\mathrm{pH}$ was measured after de-aeration with argon.

Participants were driven for approximately 10 minutes to the exposure sites in a gasoline-powered car. On arrival and hourly during each session, we made further spirometric measurements; 
on completion of each session, we asked participants to record any asthmatic symptoms. After returning to the hospital, we repeated spirometric and $\mathrm{FE}_{\mathrm{NO}}$ measurements regularly for 5 hours and measured responsiveness to methacholine; participants recorded any asthma symptoms over the ensuing 12 hours. The next morning, we repeated measurements of lung function and $\mathrm{FE}_{\mathrm{NO}}$ and collected samples of sputum induced by inhalation of a $3 \%$ sodium chloride solution from an ultrasonic nebulizer. Total cell counts were performed on a homogenized sputum sample with the use of $0.1 \%$ dithiothreitol, and differential cell counts were performed on 400 nonsquamous cells on cytospin slides. Supernatants were kept at $-80^{\circ} \mathrm{C}$ for analysis of interleukin- 8 , myeloperoxidase, and eosinophil cationic protein with the use of commercially available immunoassay kits (IL-8 DuoSet, R\&D Systems; and TiterZyme and UniCAP, Pharmacia Diagnostics AB; respectively).

\section{EXPOSURE MEASUREMENTS}

Throughout each exposure session, we measured number concentrations of ultrafine particles, using a real-time condensation particle counter (Model 3007, TSI) equipped with a ribbon laser lightscattering optical system (range, 0 to 100,000 particles per cubic centimeter; accuracy, $\pm 20 \%$ ). We collected fine particles smaller than $2.5 \mu \mathrm{m}$ in aerodynamic diameter $\left(\mathrm{PM}_{2.5}\right)$ on quartz-fiber filters, using an air sampler (16 liters per minute). The filters were used first to determine $\mathrm{PM}_{2.5}$ mass concentration gravimetrically and were then analyzed for elemental carbon according to National Institute for Occupational Safety and Health guidelines (method 5040) (Sunset Laboratory). With a sampling pump, we collected nitrogen dioxide on $\mathrm{C}_{18}$ Sep-Pak cartridges coated with potassium hydroxide and triethanolamine and subsequently analyzed the sample using ion chromatography. ${ }^{13}$ Temperature and relative humidity sensors, along with all air monitors, were located on a pushcart beside the participants.

\section{STATISTICAL ANALYSIS}

Descriptive summaries of exposure and health outcomes included means ( \pm SD) for normally distributed variables and medians with ranges for other variables. Correlations between pollutants were examined.

Associations between exposure and health outcomes were examined through comparative analysis (Oxford Street vs. Hyde Park) and pollutant-specific, exposure-response analyses. A repeated-measures, mixed-effects linear regression model was constructed to estimate average values for health outcomes, with the use of an interaction term for the categorical variables of site and time to examine the effect of the exposure site on changes in lung-function or inflammatory biomarkers. ${ }^{14} \mathrm{~A}$ random effect for individual participants accounted for similarities across sessions for each person. A spatial-power covariance structure was used to model correlations between the unequally spaced repeated measurements within each session with a decay in the strength of correlation, depending on the time between measurements. With the use of the Akaike information criterion, this structure proved to model the data adequately relative to an unstructured correlation matrix. Additional covariates, including temperature and relative humidity and, where necessary, age, sex, body-mass index, and race or ethnic group were entered as covariates. Type $3 \mathrm{~F}$ tests of the site-time interaction produced $\mathrm{P}$ values representing the overall significance of the effect of site on changes in responses over time; contrasts of means were used to examine differences between sites in changes from baseline to particular time points. To study potential effect modifiers, we tested interactions between them and site-time interaction and conducted stratified analyses.

Because pollutant concentrations varied within and between sites, we performed pollutant-specific, exposure-response analyses using mixed models, as described above. In these models, we regressed the percent change from baseline in each of the lung-function and inflammatory-biomarker variables against pollutant concentrations averaged over each exposure session. Separate, single-pollutant models for $\mathrm{PM}_{2.5}$, elemental carbon, ultrafine particles, and nitrogen dioxide were generated. Subsequently, we used two-pollutant models, in which two of the four pollutants were analyzed simultaneously.

\section{RESULTS}

As anticipated, participants with mild asthma had a higher baseline $\mathrm{FEV}_{1}$ than those with moderate asthma. They were also less likely to report limited exercise tolerance or symptoms provoked by exercise or traffic fumes (Table 1).

Median weekly nitrogen dioxide exposures were 


\begin{tabular}{|c|c|c|c|c|}
\hline Characteristic & $\begin{array}{l}\text { All Participants } \\
\qquad(\mathrm{N}=60)\end{array}$ & $\begin{array}{l}\text { Participants with } \\
\text { Mild Asthma } \\
(\mathrm{N}=31)\end{array}$ & $\begin{array}{l}\text { Participants with } \\
\text { Moderate Asthma } \\
\text { (N=29) }\end{array}$ & $P$ Value \\
\hline Female sex — no. (\%) & $29(48)$ & $14(45)$ & $15(52)$ & 0.61 \\
\hline Age $-y r$ & & & & 0.13 \\
\hline Mean & 32 & 31 & 34 & \\
\hline Range & $19-55$ & $20-49$ & $19-55$ & \\
\hline Height $-\mathrm{cm}$ & $172 \pm 8.8$ & $172 \pm 8.4$ & $171 \pm 9.3$ & 0.67 \\
\hline Body-mass index' & $23.2 \pm 3.7$ & $23.2 \pm 3.6$ & $23.2 \pm 3.9$ & 0.98 \\
\hline White race - no. $(\%) \div$ & $47(78)$ & $26(84)$ & $21(72)$ & 0.28 \\
\hline $\mathrm{FEV}_{1}-\%$ of predicted value & $88.9 \pm 10.8$ & $93.4 \pm 6.9$ & $84.1 \pm 12.3$ & $<0.001$ \\
\hline Atopy - no. (\%)』 & $42(84)$ & $24(89)$ & $18(78)$ & 0.31 \\
\hline Methacholine $\mathrm{PC}_{20}-\mathrm{mg} / \mathrm{ml}$ & $2.82 \pm 2.47$ & $2.73 \pm 2.43$ & $2.92 \pm 2.56$ & 0.78 \\
\hline Treatment with inhaled corticosteroids - no. (\%) & $37(62)$ & $12(39)$ & $25(86)$ & $<0.001$ \\
\hline Unlimited exercise tolerance — no. (\%) & $51(85)$ & $28(90)$ & $23(79)$ & 0.23 \\
\hline Asthma affected by exercise — no. (\%) & & & & 0.27 \\
\hline Yes & $44(73)$ & $20(65)$ & $24(83)$ & \\
\hline Not sure & $4(7)$ & $3(10)$ & $1(3)$ & \\
\hline Asthma affected by traffic fumes — no. (\%) & & & & 0.19 \\
\hline Yes & $17(28)$ & $7(23)$ & $10(34)$ & \\
\hline Not sure & $30(50)$ & $19(61)$ & $11(38)$ & \\
\hline
\end{tabular}

* Plus-minus values are means \pm SD. P values are for comparisons according to the severity of asthma. $\mathrm{FEV}_{1}$ denotes forced expiratory volume in 1 second.

$\uparrow$ The body-mass index is the weight in kilograms divided by the square of the height in meters.

Race was self-reported.

$\int$ Ten participants (six with moderate asthma) did not have skin-prick tests.

q Methacholine $\mathrm{PC}_{20}$ denotes the concentration of methacholine required to provoke a $20 \%$ decrease in the $\mathrm{FEV}_{1}$.

not significantly different before exposure at the two sites (Table 2). Participants had significantly higher exposures to $\mathrm{PM}_{2.5}$, ultrafine particles, elemental carbon, and nitrogen dioxide on Oxford Street than in Hyde Park. Spearman's rank-correlation coefficients for exposures to the four pollutants were as follows: 0.58 for the correlation of nitrogen dioxide with both ultrafine particles and elemental carbon, 0.62 for the correlation of $\mathrm{PM}_{2.5}$ with ultrafine particles, and 0.84 for the correlation of ultrafine particles with elemental carbon. (Complete information is provided in $\mathrm{Ta}$ ble A1 of the Supplementary Appendix, available with the full text of this article at www.nejm.org.)

Average daily peak expiratory flow, symptoms, and use of asthma medication did not differ significantly in the week before exposures at the two sites. Similarly, there were no significant differences between the sites in mean $\mathrm{FEV}_{1}$, FVC, or $\mathrm{FEF}_{25-75}$ at baseline in the hospital or on arrival at the site (Table 2). On the whole, changes over time in mean $\mathrm{FEV}_{1}$ and $\mathrm{FVC}$ differed significantly between the sites $(\mathrm{P}=0.04$ and $\mathrm{P}=0.01$, respectively), but there were no significant differences between sites in the changes in $\mathrm{FEF}_{25-75}$. Mean $\mathrm{FEV}_{1}$ (percent of the predicted value) was lower after 1 hour of exposure at both sites. The subsequent decrement was greater and more sustained for Oxford Street, with a maximal decline at 2 hours $(-6.1 \%$, vs. $-1.9 \%$ for Hyde Park; $\mathrm{P}<0.001)$. The differences between sites remained significant at every time point $(\mathrm{P}<0.05)$ until 22 hours after exposure. Among participants with moderate asthma, the decline in $\mathrm{FEV}_{1}$ was greater for Oxford Street than for Hyde Park, but the difference was not significant.

The pattern for mean FVC (percent of predicted value) was similar (Fig. 1), with a maximum drop after 2 hours $(-5.4 \%$ for Oxford Street vs. $-1.6 \%$ for Hyde Park, $\mathrm{P}<0.005)$. The differences in changes in FVC between the two sites were significant at each time point between 2 and 5 hours after 


\begin{tabular}{|c|c|c|c|}
\hline Variable & Oxford Street & Hyde Park & P Value \\
\hline \multicolumn{4}{|l|}{ Exposure } \\
\hline \multicolumn{3}{|l|}{ Nitrogen dioxide in previous week $\left(\mu \mathrm{g} / \mathrm{m}^{3}\right)$} & 0.90 \\
\hline Median & 23.5 & 22.3 & \\
\hline Range & $1.46-135$ & $0.49-61.6$ & \\
\hline \multicolumn{3}{|l|}{ Temperature $\left({ }^{\circ} \mathrm{C}\right)$} & 0.04 \\
\hline Median & 10.8 & 9.1 & \\
\hline Range & $4-17.1$ & $2.5-17.2$ & \\
\hline \multicolumn{3}{|l|}{ Relative humidity (\%) } & 0.03 \\
\hline Median & 66 & 76 & \\
\hline Range & $41.9-93.2$ & $43.2-93.3$ & \\
\hline \multicolumn{3}{|l|}{$\mathrm{PM}_{2.5}\left(\mu \mathrm{g} / \mathrm{m}^{3}\right)$} & $<0.001$ \\
\hline Median & 28.3 & 11.9 & \\
\hline Range & $13.9-76.1$ & $3-55.9$ & \\
\hline \multicolumn{3}{|l|}{ Ultrafine particles (thousands $/ \mathrm{cm}^{3}$ ) } & $<0.001$ \\
\hline Median & 63.7 & 18.3 & \\
\hline Range & $39.5-92.4$ & $10.3-37.1$ & \\
\hline \multicolumn{3}{|l|}{ Elemental carbon $\left(\mu \mathrm{g} / \mathrm{m}^{3}\right)$} & $<0.001$ \\
\hline Median & 7.5 & 1.3 & \\
\hline Range & $3.9-16$ & $0.4-6.7$ & \\
\hline \multicolumn{3}{|l|}{ Nitrogen dioxide $\left(\mu \mathrm{g} / \mathrm{m}^{3}\right)$} & $<0.001$ \\
\hline Median & 142 & 21.7 & \\
\hline Range & $10.7-289$ & $2.4-146$ & \\
\hline \multicolumn{3}{|l|}{$\mathrm{PM}_{10}\left(\mu \mathrm{g} / \mathrm{m}^{3}\right) \dagger$} & 0.03 \\
\hline Median & 125 & 72 & \\
\hline Range & $62-161$ & $60-100$ & \\
\hline \multicolumn{4}{|l|}{ Baseline lung function } \\
\hline $\mathrm{FEV}_{1}$ & $93.8 \pm 11.0$ & $92.2 \pm 11.4$ & 0.44 \\
\hline FVC & $103.5 \pm 12.4$ & $102.8 \pm 11.8$ & 0.76 \\
\hline $\mathrm{FEF}_{25-75}$ & $65.6 \pm 16.8$ & $63.4 \pm 18.6$ & 0.51 \\
\hline \multicolumn{4}{|c|}{$\begin{array}{l}\text { Plus-minus values are means } \pm \text { SD. P values are for within-participant comparisons between Oxford Street and Hyde } \\
\text { Park. } \mathrm{PM}_{2.5} \text { denotes particles less than } 2.5 \mu \mathrm{m} \text { in aerodynamic diameter, } \mathrm{PM}_{10} \text { particles less than } 10 \mu \mathrm{m} \text { in diameter, } \\
\mathrm{FEV} \mathrm{V}_{1} \text { forced expiratory volume in } 1 \text { second, } \mathrm{FVC} \text { forced vital capacity, and } \mathrm{FEF}_{25-75} \text { forced expiratory flow at } 25 \text { to } 75 \% \\
\text { of vital capacity. } \\
\text { - Values are for fixed-site measurements only. }\end{array}$} \\
\hline
\end{tabular}

the start of exposure $(\mathrm{P}<0.05)$ and were significantly greater among participants with moderate asthma than among those with mild asthma $(\mathrm{P}=0.008)$. There were no significant differences in the mean change in $\mathrm{FEF}_{25-75}$ (percent of predicted value) between sites or in the methacholine $\mathrm{PC}_{20}$ value 5 hours after exposure.

Changes in respiratory symptoms during and after exposures were small. Participants with mild asthma reported more symptoms after exposures on Oxford Street (both immediately afterward and 5 hours afterward) than after exposures in Hyde Park, but the differences were not significant. The use of treatments for asthma relief over the 7-day period after exposure did not differ significantly between the two sites.

There were no significant differences in the changes in mean $\mathrm{FE}_{\mathrm{NO}}$ between exposures on $\mathrm{Ox}$ - 


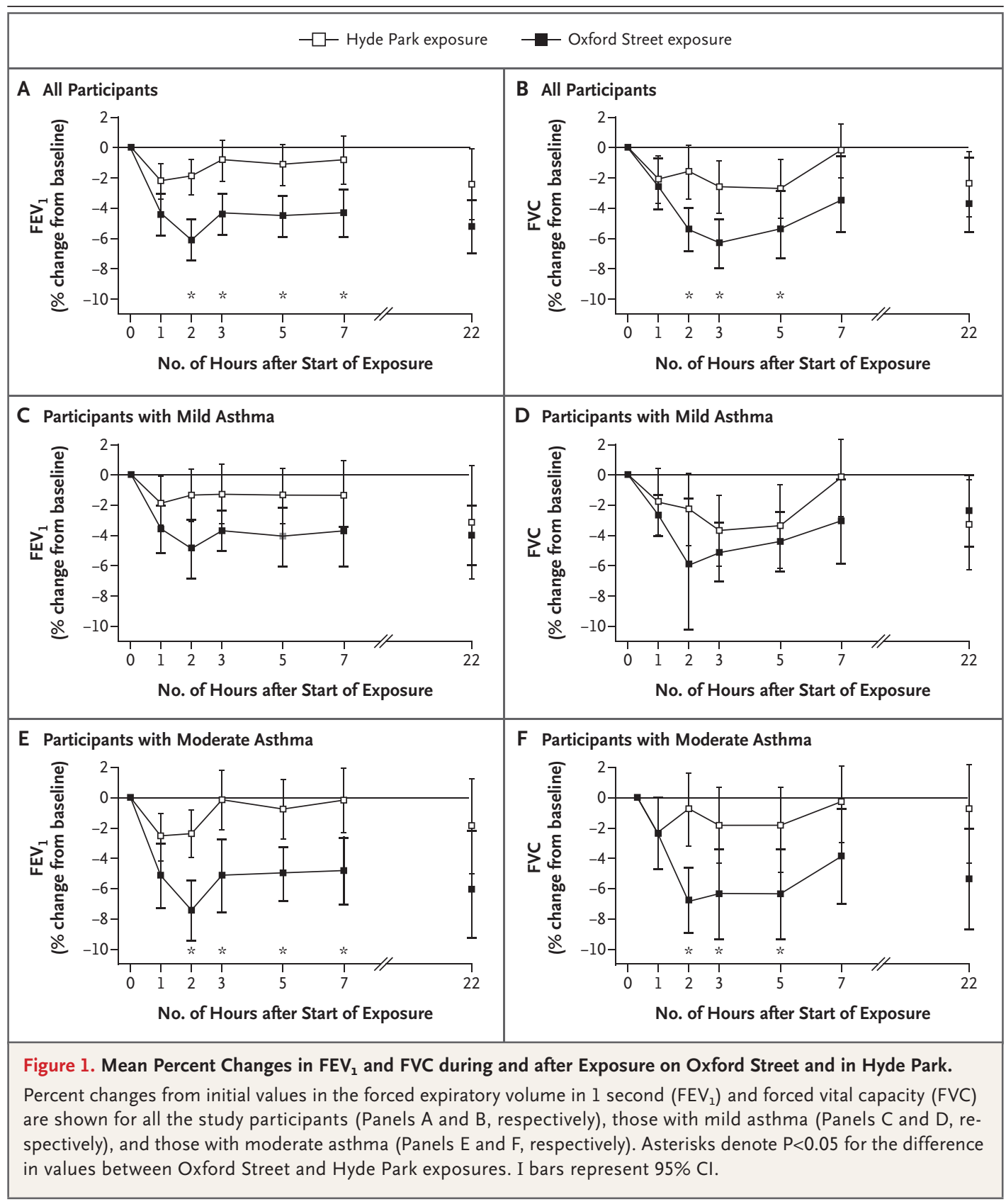

ford Street and those in Hyde Park. There were greater decreases in the $\mathrm{pH}$ of exhaled breath condensate after exposure on Oxford Street - 1.16\%, as compared with $0.88 \%$ in Hyde Park at 3 hours, and $-1.90 \%$ as compared with $0.04 \%$ in Hyde Park at 6 hours (Fig. 2). The changes were not significantly greater among participants with moderate asthma.

The sputum myeloperoxidase concentration at 24 hours was higher after exposure on Oxford
Street (24.5 ng per milliliter) than after exposure in Hyde Park (4.2 ng per milliliter, $\mathrm{P}=0.01$ ) (Fig. 2). Sputum neutrophil counts and interleukin-8 concentrations were strongly correlated with myeloperoxidase ( $\mathrm{P}<0.001$ for both comparisons), and each was higher after Oxford Street exposures; only in the case of sputum neutrophil counts (for all participants), however, was this difference significant. There were no significant differences in sputum eosinophil counts or eosinophil cationic 


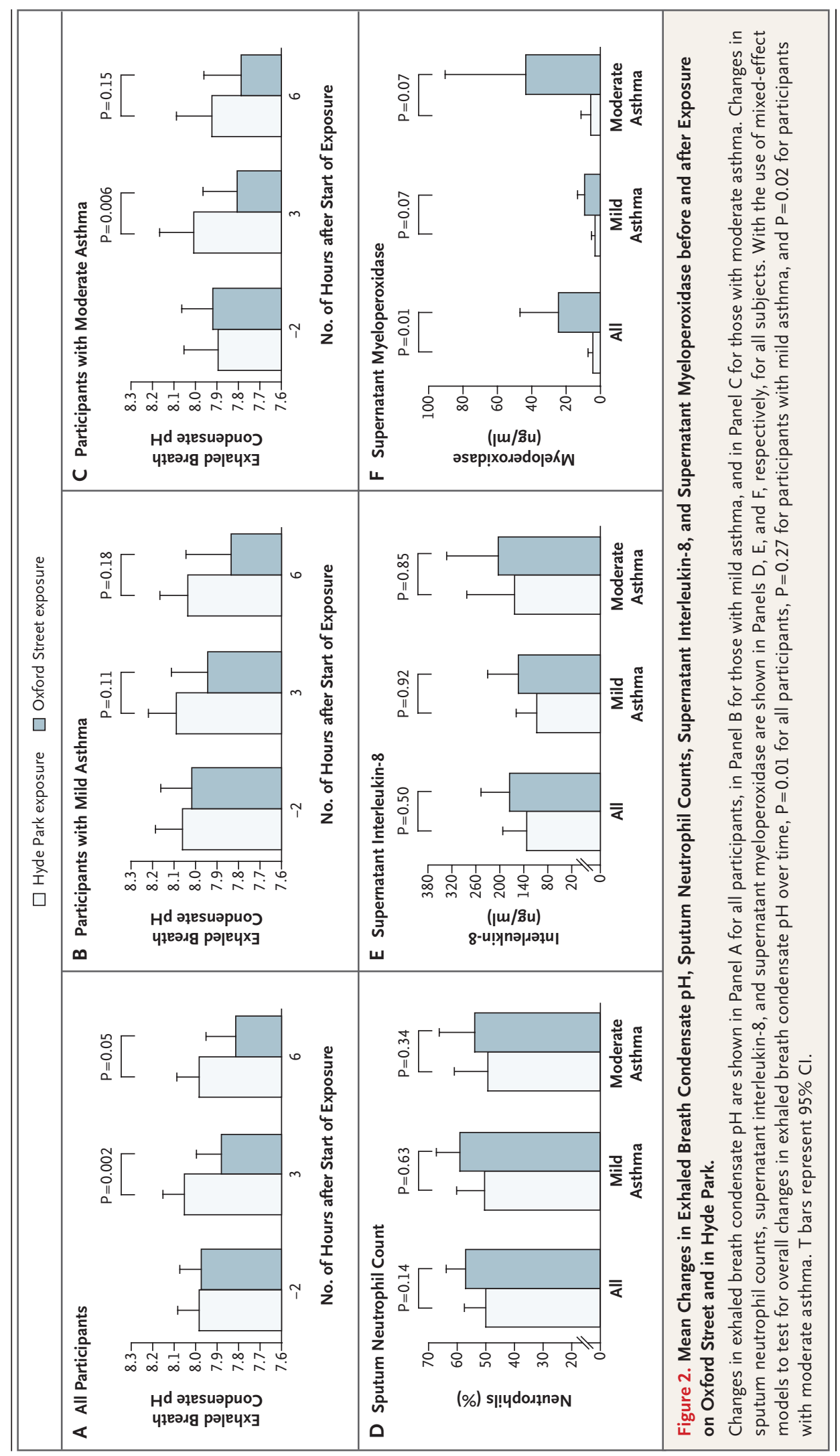


protein levels. We found no consistent evidence of an interaction between these health outcomes and the other variables listed in Table 1 (and Table A2 in the Supplementary Appendix).

Reductions in $\mathrm{FEV}_{1}, \mathrm{FVC}, \mathrm{FEF}_{25-75}$, and exhaled breath condensate $\mathrm{pH}$ were associated with ultrafine-particle exposures at most time points (Fig. 3); these reductions were also associated, although less consistently, with elemental carbon exposures (for ultrafine particles, $\mathrm{P}=0.02, \mathrm{P}=0.27, \mathrm{P}=0.11$, and $\mathrm{P}=0.03$, respectively; for elemental carbon, $\mathrm{P}=0.04, \mathrm{P}=0.11, \mathrm{P}=0.32$, and $\mathrm{P}=0.24$, respectively). Elemental carbon exposures were also associated with increases in $\mathrm{FE}_{\mathrm{NO}}$ concentrations $(\mathrm{P}=0.06)$. For nitrogen dioxide, the associations were similar but less pronounced; for $\mathrm{PM}_{2.5}$, there were no consistent associations. Increased sputum myeloperoxidase concentrations were associated with ultrafine-particle exposure $(\mathrm{P}=0.03)$. There were no associations between sputum cell counts or interleukin-8 and any of the pollutant constituents. After adjustment for copollutants in the two-pollutant models, the effects of ultrafine particles and elemental carbon remained the most consistent and were significant (Table A3 in the Supplementary Appendix).

\section{DISCUSSION}

We examined the functional and inflammatory effects on asthma of real-life exposure to roadside diesel traffic. In adults with asthma, walking for 2 hours at a leisurely pace along a street where only diesel-powered vehicles were permitted resulted in a significant but essentially asymptomatic reduction in lung function. Although the changes were small, they were greater than those provoked by walking in a nearby park and were more pronounced among study participants whose asthma was more severe. These changes were accompanied by inflammatory changes in sputum and exhaled breath condensate.

The inflammatory response was predominantly neutrophilic, with raised levels of myeloperoxidase and interleukin-8 in sputum supernatants; we did not detect, even in participants with more severe asthma, an eosinophilic response characteristic of asthmatic inflammation. In association with the drop in $\mathrm{FEV}_{1}$, we found a twofold increase in exhaled-breath-condensate hydrogen ions after exposure on Oxford Street. Acute asthma may be accompanied by airway acidification, with an in- crease in hydrogen ions by a factor of more than $100,{ }^{15}$ perhaps reflecting inhibition of local epithelial proton pumps during airway inflammation. ${ }^{16}$ Thus, intracellular acidosis related to the inflammatory process may be reflected in reduced airway $\mathrm{pH}^{17}$

It has been suggested that any harmful respiratory effects of acute exposure to diesel exhaust are attributable more to its particulate content than to its gaseous content. ${ }^{18}$ In addition to coarse particles (2.5 to $10 \mu \mathrm{m}$ in diameter), diesel exhaust contains, in far greater numbers, ultrafine particles $(<0.1 \mu \mathrm{m}$ in diameter). In our study, the most consistent relationships between changes in respiratory variables and specific pollutant concentrations were for ultrafine particles and elemental carbon, a finding consistent with growing evidence that the adverse respiratory effects of diesel-generated particles are attributable to those in the very small size range. ${ }^{19-23}$ With their higher ratio of surface area to mass, ultrafine particles can adsorb greater fractions of potentially toxic substances onto their surface, and they are deposited more deeply and in greater numbers within the lung than are larger particles. Furthermore, the carbon core of elemental carbon particles is highly adsorptive. ${ }^{24}$ Differences in the concentrations of ultrafine particles and elemental carbon between Oxford Street and Hyde Park were substantially larger than the differences in concentration between $\mathrm{PM}_{2.5}$ and particles less than $10 \mu \mathrm{m}$ in diameter. However, our findings cannot be taken as a demonstration of a causal association with ultrafine particles and elemental carbon, since these may simply be a sensitive proxy for the entirety of a roadside diesel-traffic exposure, which is composed not only of the complex diesel exhaust mixture but also of resuspended coarse, thoracic particles (small enough to enter the thorax) from road dust and engine or tire debris, which we did not measure.

Previous studies of the direct effects of diesel exhaust on asthma in humans have been conducted under laboratory conditions, with fresh diesel fumes, from which gaseous constituents may have been removed ("scrubbed"), or reconstituted diesel exhaust material delivered to subjects in an exposure chamber. ${ }^{6,7,11,25-27}$ The findings of these studies have not been entirely consistent, and none of them have demonstrated an effect on spirometric lung function, despite the use of much higher concentrations of diesel particles than 


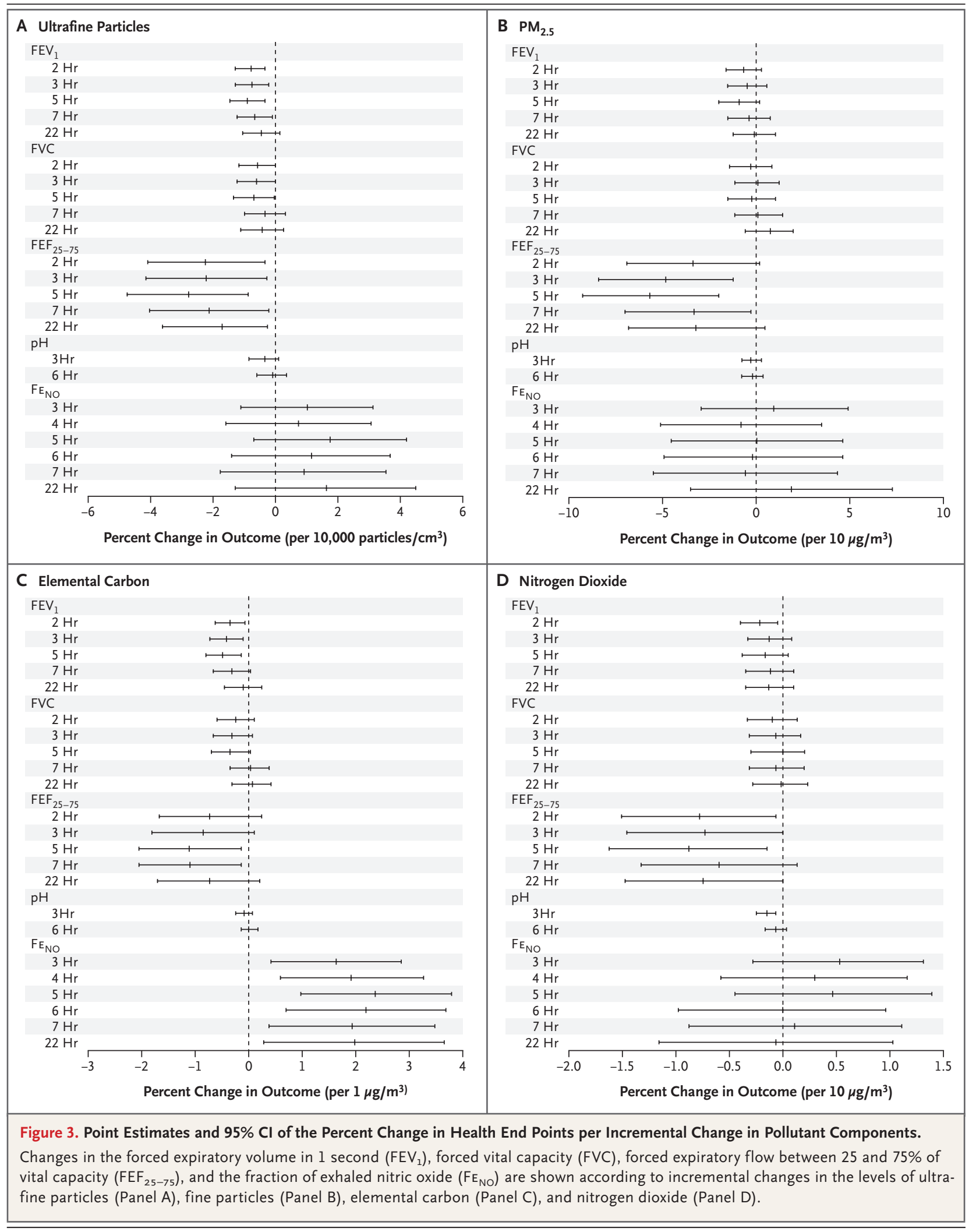


those we measured on Oxford Street. The discrepancies between the findings of other studies and our own may be due to the complexity of the natural pollutant mixture we studied, with interactions between particulates and other pollutants, or to the possibility that reconstituted or scrubbed diesel exhaust mixtures substantially reduce the proportion of ultrafine particles. In addition, we studied people with more severe asthma. Svartengren et al., ${ }^{28}$ in a realistic study of brief exposure to traffic pollution in a road tunnel, also failed to find any effect on $\mathrm{FEV}_{1}$ but reported more symptoms than we observed. Personal exposures to $\mathrm{PM}_{2.5}$ and nitrogen dioxide were much higher in that study, but the study participants had milder asthma than did the participants in our study. On the other hand, the inflammatory responses we observed, particularly the increase in sputum neutrophils and myeloperoxidase, were similar in nature to those in studies of controlled, chamber exposures. ${ }^{8,10,26,28}$

Our primary motive was to understand the effects of typical exposures to an urban atmosphere dominated by diesel exhaust. To this end, we selected a setting where only diesel traffic was allowed and used a randomized, crossover design limited to the winter months to avoid confounding exposure to pollens, thereby removing or controlling for most important confounding factors. Nonetheless, we recognize some limitations of our study, including the impossibility of blinding participants and the inability to exclude the possibility of subjective responses, particularly with symptom reporting. However, the internal consistency of our findings and the changes in variables over which the participants had no control make it very improbable that our results arose entirely from a subjective bias. Another difficulty arises from potentially confounding exposures that we did not measure. For example, a walk on Oxford Street is likely to be a more stressful experience than a walk in a quiet park, and it is possible that some of the responses we measured were induced by factors associated with stress, particularly noise. ${ }^{29}$ In addition, because we did not study a reference group of people without asthma, we cannot be sure that our findings are specific to people with asthma, although the more pronounced responses in the participants with more severe disease suggest that the findings are specific. Finally, we did not study exposure to gasoline-powered traffic and therefore cannot conclude that diesel traffic is more toxic than other types.

Our observations serve as a direct demonstration and explanation of the epidemiologic evidence that associates exposure to diesel traffic with the severity of asthma and of the symptoms that many patients with asthma report after exposure to diesel exhaust. The changes in our primary end point $\left(\mathrm{FEV}_{1}\right)$ were small and unaccompanied by clinically significant symptoms but would be more important in patients with more compromised lung function. Without further study, however, we do not believe that these findings should deter most patients with asthma from visiting or working in busy urban environments. Our design has considerable advantages over orthodox chamber studies and could readily be adapted to assess therapeutic strategies in the prophylaxis of traffic responses in asthma or other cardiorespiratory diseases.

Supported by the Health Effects Institute through a Research Agreement (02-9) with the University of Medicine and Dentistry of New Jersey.

Dr. Cullinan reports serving as a member of the Expert Advisory Panel for Air Quality Standards for the U.K. government. Dr. Chung reports receiving advisory-board fees from Astra-Zeneca, GlaxoSmithKline, Novartis, Merck, and Mundi-Pharma, consulting fees from Gilead, and research support from GlaxoSmithKline. No other potential conflicts of interest relevant to this article were reported.

We thank the volunteers who took part in this study, Sally Meah for her help with recruitment and clinical measurements at Royal Brompton Hospital, and Frank Speizer and Terry Tetley for helpful advice.

\section{REFERENCES}

1. Goldsmith CA, Kobzik L. Particulate air pollution and asthma: a review of epidemiological and biological studies. Rev Environ Health 1999;14:121-34.

2. Janssen NA, Brunekreef B, van Vliet P, et al. The relationship between air pollution from heavy traffic and allergic sensitization, bronchial hyperresponsiveness, and respiratory symptoms in Dutch schoolchildren. Environ Health Perspect 2003; 111:1512-8.
3. Polosa R, Salvi S, Di Maria GU. Allergic susceptibility associated with diesel exhaust particle exposure: clear as mud. Arch Environ Health 2002;57:188-93.

4. Air Quality Expert Group. Particulate matter in the United Kingdom. London: Defra, 2005.

5. Manchester-Neesvig JB, Schauer JJ, Cass GR. The distribution of particlephase organic compounds in the atmosphere and their use for source apportion- ment during the Southern California Children's Health Study. J Air Waste Manag Assoc 2003;53:1065-79.

6. Nordenhäll C, Pourazar J, Ledin MC, Levin JO, Sandstrom T, Adelroth E. Diesel exhaust enhances airway responsiveness in asthmatic subjects. Eur Respir J 2001; 17:909-15.

7. Rudell B, Ledin MC, Hammarström U, Stjernberg N, Lundbäck B, Sandström T. Effects on symptoms and lung function 
in humans experimentally exposed to diesel exhaust. Occup Environ Med 1996;53: 658-62.

8. Nordenhäll C, Pourazar J, Blomberg A, Levin JO, Sandstrom T, Adelroth E. Airway inflammation following exposure to diesel exhaust: a study of time kinetics using induced sputum. Eur Respir J 2000; 15:1046-51.

9. Rudell B, Blomberg A, Helleday R, et al. Bronchoalveolar inflammation after exposure to diesel exhaust: comparison between unfiltered and particle trap filtered exhaust. Occup Environ Med 1999; 56:527-34.

10. Salvi SS, Nordenhall C, Blomberg A, et al. Acute exposure to diesel exhaust increases IL-8 and GRO-alpha production in healthy human airways. Am J Respir Crit Care Med 2000;161:550-7.

11. Stenfors N, Nordenhäll C, Salvi SS, et al. Differentairway inflammatory responses in asthmatic and healthy humans exposed to diesel. Eur Respir J 2004;23:82-6. 12. Global Initiative for Asthma (GINA) home page. (Accessed November 9, 2007, at www.ginasthma.com/Guidelineitem. asp.)

13. Hisham MWM, Grosjean J. Sampling of atmospheric nitrogen dioxide using triethanolamine: interference from peroxyacetyl nitrate. Atmos Environ 1990;24:2523.

14. SAS for mixed models. Cary, NC: SAS Institute, 2006.

15. Hunt JF, Fang K, Malik R, et al. Endogenous airway acidification: implica- tions for asthma pathophysiology. Am J Respir Crit Care Med 2000;161:694-9.

16. Fischer H, Widdicombe JH, Illek B. Acid secretion and proton conductance in human airway epithelium. Am J Physiol Cell Physiol 2002;282:C736-C743.

17. Kaufman DS, Goligorsky MS, Nord EP, Graber ML. Perturbation of cell $\mathrm{pH}$ regulation by $\mathrm{H} 2 \mathrm{O} 2$ in renal epithelial cells. Arch Biochem Biophys 1993;302:24554.

18. Abe S, Takizawa H, Sugawara I, Kudoh S. Diesel exhaust (DE)-induced cytokine expression in human bronchial epithelial cells: a study with a new cell exposure system to freshly generated $\mathrm{DE}$ in vitro. Am J Respir Cell Mol Biol 2000; 22:296-303.

19. Penttinen $P$, Timonen KL, Tiittanen $P$, Mirme A, Ruuskanen J, Pekkanen J. Ultrafine particles in urban air and respiratory health among adult asthmatics. Eur Respir J 2001;17:428-35.

20. Peters A, Wichmann HE, Tuch $T$, Heinrich J, Heyder J. Respiratory effects are associated with the number of ultrafine particles. Am J Respir Crit Care Med 1997;155:1376-83.

21. Li N, Hao M, Phalen RF, Hinds WC, Nel AE. Particulate air pollutants and asthma: a paradigm for the role of oxidative stress in PM-induced adverse health effects. Clin Immunol 2003;109:250-65. 22. Nel A. Air pollution-related illness: effects of particles. Science 2005;308:8046. [Erratum, Science 2005;309:1326.]
23. Kulkarni N, Pierse N, Rushton L, Grigg J. Carbon in airway macrophages and lung function in children. $\mathrm{N}$ Engl $\mathrm{J}$ Med 2006;355:21-30.

24. Oberdörster G, Oberdörster E, Oberdörster J. Nanotoxicology: an emerging discipline evolving from studies of ultrafine particles. Environ Health Perspect 2005;113:823-39.

25. Gong H Jr, Sioutas C, Linn WS. Controlled exposures of healthy and asthmatic volunteers to concentrated ambient particles in metropolitan Los Angeles. Res Rep Health Eff Inst 2003;118:1-36.

26. Nightingale JA, Maggs R, Cullinan P, et al. Airway inflammation after controlled exposure to diesel exhaust particulates. Am J Respir Crit Care Med 2000;162:1616.

27. Rudell B, Sandstrom T, Hammarstrom U, Ledin ML, Horstedt P, Stjernberg $\mathrm{N}$. Evaluation of an exposure setup for studying effects of diesel exhaust in humans. Int Arch Occup Environ Health 1994;66:77-83.

28. Svartengren M, Strand V, Bylin G, Jarup L, Pershagen G. Short-term exposure to air pollution in a road tunnel enhances the asthmatic response to allergen. Eur Respir J 2000;15:716-24.

29. Ising $\mathrm{H}$, Lange-Asschenfeldt $\mathrm{H}$, Lieber GF, Weinhold H, Eilts M. Respiratory and dermatological diseases in children with long-term exposure to road traffic immissions. Noise Health 2003;5:41-50.

Copyright (c) 2007 Massachusetts Medical Society.

RECEIVE IMMEDIATE NOTIFICATION WHEN

A JOURNAL ARTICLE IS RELEASED EARLY

To be notified when an article is released early on the Web and to receive the table of contents of the Journal by e-mail every Wednesday evening, sign up through our Web site at www.nejm.org 